\section{eRASing asthma}

\section{By Matthew Mikulski, Staff Writer}

The mechanistic rationale for hypertension drugs that block the reninangiotensin system in the circulation is clear: inhibit the process by which vasoconstriction occurs and blood pressure will go down. Cornell University researchers now suggest that renin-angiotensin system inhibitors also could have a role in asthma and other diseases involving bronchoconstriction. ${ }^{1}$

Hypertension companies that want to see animal data before considering bronchoconstriction indications will not have to wait very long, as follow-up manuscripts are already in preparation.

Circulating renin originates from the kidneys, which secrete the enzyme in response to decreases in blood volume and renal perfusion. Renin sits atop the renin-angiotensin system (RAS), and the eventual result of renin secretion is the production of angiotensin II, a peptide that promotes vasoconstriction.

Randi Silver, associate professor of physiology and biophysics at Cornell and an author on the paper, published in the Proceedings of the National Academy of Sciences, told SciBX that researchers have speculated about local, tissue-specific roles of renin for at least a decade.

Silver and colleagues previously identified cardiac mast cells as a source of renin outside the kidneys. ${ }^{2}$ The group later extended the

Figure 1. Renin-angiotensin signaling in the airway.

Bronchoconstriction is triggered by renin released by mast cells residing in the lungs, a finding that opens the door to new treatments targeting the renin-angiotensin pathway for asthma and other respiratory diseases.

As shown in this bronchiole cross-section graphic, in asthmatics, an increased number of mast cells are found on the epithelial surface and the smooth muscle layer in the bronchi. Anaphylaxis triggers mast cell degranulation, releasing renin as well as histamine, heparin, serine proteases, prostaglandin D2 and leukotriene C4 (a).

Renin released from mast cells catalyzes the conversion of aogen into angiotensin I (b), which is then converted into angiotensin II by angiotensin-converting enzyme (ACE) generated by the airway epithelial cells (c). Angiotensin II then activates angiotensin II receptors on airway smooth muscle cells (d), triggering muscle contraction and bronchoconstriction.

There are marketed mast cell stabilizers for asthma that inhibit mast cell degranulation, such as cromolyn and nedocromil. Other compounds in the clinic or on the market inhibit renin, ACE or angiotensin II receptor, but these are mainly for cardiovascular indications. finding by showing that renin released by mast cell degranulation in both mouse and pig hearts stimulated excessive norepinephrine production and caused ventricular fibrillation. ${ }^{3}$

The key finding in the recent PNAS paper is that renin produced by mast cells in the lungs contributes to bronchoconstriction.

"Even if others had considered RAS as having a role in asthma, they never realized that the rate-limiting step-renin production-was coming from cells directly in the lungs," said Roberto Levi, professor of pharmacology at Cornell and an author on the paper.

In bronchial rings excised from rats, mast cell degranulation led to angiotensin II-mediated smooth muscle contraction. Three agentsthe renin inhibitor BILA2157, the angiotensin II type 1 (AT1) receptor inhibitor EXP3174 and the mast cell stabilizer cromolyn-each reduced contractile responses by about $50-65 \%$.

EXP3174 is the active metabolite of the antihypertensive drug losartan, which is marketed alone as Cozaar or together with hydrochlorothiazide as Hyzaar by Merck \& Co. Inc. BILA2157 was developed by Boehringer Ingelheim $\mathrm{GmbH}$ over a decade and a half ago, but the company did not end up advancing the compound into clinical development.

The researchers also found enzymatically active renin in mast cells isolated from human lung tissue.

Silver and colleagues are planning to follow up their results by testing RAS-blocking drugs in mouse models of asthma, idiopathic pulmonary fibrosis (IPF) and chronic obstructive pulmonary disorder (COPD).

The researchers are also considering studies in excised human upper airway tissue. The group also will continue studying the role of local RAS activation in kidney fibrosis and diabetes.

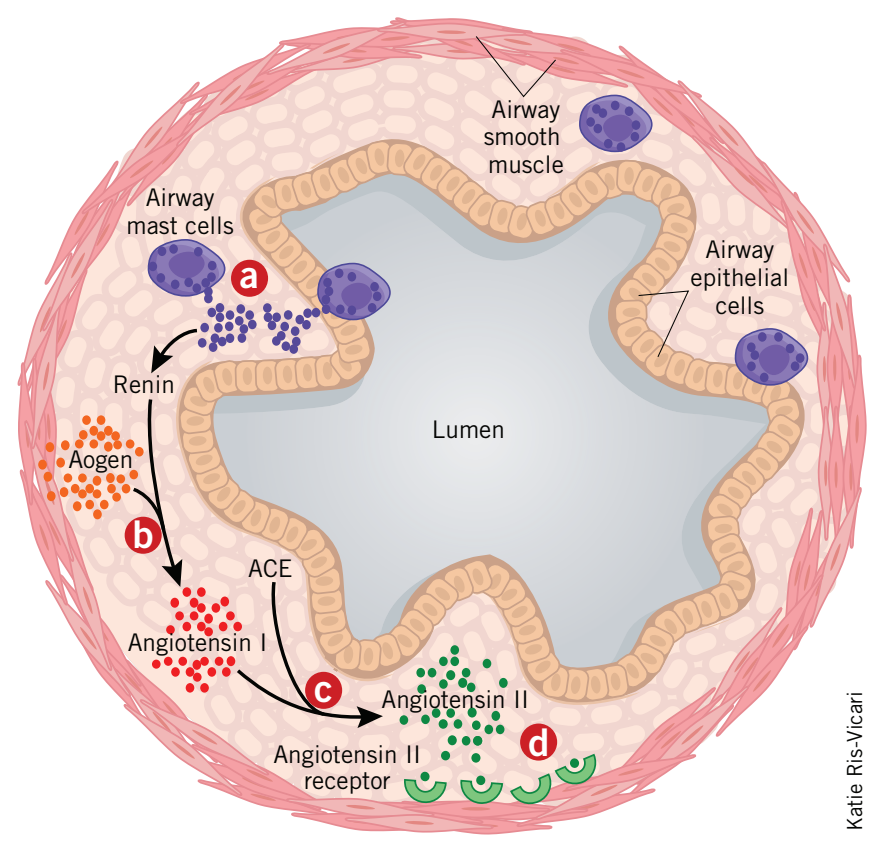




\section{TARGETS \& MECHANISMS}

There is no shortage of approved drugs targeting the RAS (see Figure 1, "Renin-angiotensin signaling in the airway"). The first AT1 receptor blocker was approved more than a decade ago, and angiotensin-converting enzyme (ACE) inhibitors have been around for more than 20 years. By contrast, the first renin inhibitor entered the market less than a year ago: Tekturna aliskiren from Speedel and Novartis AG received FDA approval in March 2007 to treat hypertension. ${ }^{4}$

Craig Fox, head of respiratory programs at Argenta Discovery Ltd., told SciBX that the preliminary results support several potential therapeutic applications. For example, he said an inhaled formulation of an AT1 receptor antagonist could target lung mast cells and remain relatively absent from circulation. As a maintenance therapy for asthma patients, such a product might reduce the need for long-acting $\beta$-2 agonists (LA $\beta A s)$, for which "there are some safety concerns," Fox said.

Marketed LA $\beta$ As for asthma and COPD include Serevent salmeterol from GlaxoSmithKline plc and Xopenex levalbuterol from Sepracor Inc. The labels for drugs in this class note that the compounds can induce bronchospasm and are associated with a small increase in the risk of asthma-related death.

Argenta's lead development program is for an inhaled combination of ADC4022 and corticosteroids. ADC4022 is a steroid sensitizer with an undisclosed mechanism of action. The combination is in Phase IIa testing for severe asthma and COPD, with data expected this year.

Klaus Dembowski, managing director of Speedel's Speedel Experimenta Ltd. research unit, said Silver's research represents "an interesting story" but that he wants "confirmative data-proof-of-concept in animal models."

Speedel should not have to wait very long. Silver is working on two additional manuscripts that document results in both IPF and tubulointerstitial fibrosis-a hallmark of end-stage renal disease. The papers, which she hopes will be accepted for publication within the next six months, will detail the team's research in mice lacking mast cells while also reporting on the pharmacological inhibition of RAS.

Another question worth addressing, Dembowski noted, is how much RAS contributes to the overall contraction that occurs in airway diseases. Based on both published and unpublished results, Silver said she expects that about half of the bronchial response seen in guinea pig tissues is due to renin released by mast cells, with histamine accounting for the other half.

Thus, Silver said, one strategy for treating asthma could involve combinations of generic drugs that have "been around a long while, are easy to get and have few serious side effects." For example, she said, a reprofiling company should consider an inhaled combination of a long-acting formulation of cromolyn and a generic antihistamine such as mepyramine.

Unpublished data from Silver's lab indicate that mepyramine's bronchoconstriction-reducing effects are additive to those of agents that block the RAS. Contrary to existing thought, she said, cromolyn does not appear to work by inhibiting histamine release but instead might inhibit renin release by stabilizing mast cells.

The remaining hurdle would be to develop a long-acting form of cromolyn and to formulate the combination for an inhaler, Silver noted.

The researchers have filed for a U.S. patent covering the therapeutic inhibition of angiotensin II produced locally from mast cell-derived renin. The pending IP is available for licensing.

\section{REFERENCES}

1. Veerappan, A. et al. Proc. Nat. Acad. Sci. USA; published online Jan. 17, 2008; doi:10.1073/pnas.0709739105

Contact: Randi B. Silver, Weill Cornell Medical College, New York, N.Y. e-mail: rbsilve@med.cornell.edu

2. Silver, R. et al. Proc. Nat. Acad. Sci. USA 101, 13607-13612 (2004)

3. Mackins, C. et al. J. Clin. Invest. 116, 1063-1070 (2006)

4. BioCentury 15(12), B10; March 12, 2007

COMPANIES AND RESEARCH INSTITUTIONS MENTIONED

Argenta Discovery Ltd., Harlow, Essex, U.K.

Boehringer Ingelheim GmbH, Ingelheim, Germany

Cornell University, Ithaca, N.Y.

GlaxoSmithKline plc (LSE:GSK; NYSE:GSK), London, U.K.

Merck \& Co. Inc. (NYSE:MRK), Whitehouse Station, N.J.

Novartis AG (NYSE:NVS; SWX:NOVN), Basel, Switzerland

Sepracor Inc. (NASDAQ:SEPR), Marlborough, Mass.

Speedel (SWX:SPPN), Basel, Switzerland 